EXTIRPATION OF A LARGE TUMOUR.

By John Charles Hali, M.D., M.R.C.S., East Retford.

The Reporter for The Lavere of a case in which an operation was last week performed on a patient under the influence of the vapour of ether, remarked, "All we want at present aro facts faithfully recorded, whatever the result." I am quite aware it is impossible to draw a correct conclusion from one or two operations, and therefore feel it a duty $I$, in common with every other medical man, owe to the profession, to record from time to time the result of our experience. I last weele mentioned two operations, performed by nyself, on patients when under the effects of this all-powerful remedy. I now communicate the result of another operation, far more severe - an operation for the removal of an enormous tumour, which required a long, difficult, and tedious dissection, and which could only be effected slowly, and with very grent care, from the nature of the highly important parts in dire contact with the tumour.

CASE-Mrs. G-M a a F. Blagg, Esq., Surgeon, of South Leverton, to give iny opinion on the case of a lady who had been unler his care for a tumour on the sile of the neck. The substance was first observed about fourteen years since, and had slowly increased, until two years ago, when it began very rapidly to enlarge, aud appeared, to use the lady's own words, "daily to press more upon her windpipe." It extended from the side of the trachea, downwards and backwards, over the sterno-cleidomastoideus muscle, its anterior edge, as far as we could ascertain, being in close contact with the carotid artery. As the tumour was rapidly increasing, and as it already interfered a good deal with the comfort of Mrs. G_- I proposed its immediate removal," and my friend $\mathrm{Mr}$. Blagg agreeing with me, it was fixed that I should remove it, which, with his valuable assistance, I accomplished, without giving the slightest pain to the patient.

January 25 th, 1847.-Mrs. G- willingly consented to inhale the ether, which she did from the apparatus of Mr. Robinson; in five minutes she said she "was going off"-the pulse had then risen from 70 to 100 -in eight minutes it was $130-$ the pupils dilated, the breathing quick, but no stertor. I then pinched the hand sharply, and spoke to her; she appenred insensible to pain; the face was covered with moisture. I now commenced the operation by making an incision from six to seven inches in length through the skin, and then proceeded carefully to dissect out the tumour, a work of considerable time and difficulty, from the firm nature of the adhesions of the tumour to the surrounding tissues, as well as from the very great cantion necessary, from the very important parts in immediate contact; the inner borders of the sterno-cleidomastoid muscle had been partially displaced, and the carotid artery was in close contact with the tumour, and could be felt, both by Mr. Blagg and myself, pulsating at the bottom of the wound. The operation lasted about sixteen minutes, during the whole of which time she only moved twice, when the vapour tube was again placed in her mouth; she answered somewhat incoherently, if questioned during the operation, and appeared perfectly indifferent to, if not unconscious of, what was going on. There was not the least quivering of the muscles on the first application of the knife. MIr. Blagg remarked it appeared as thongh I was demonstrating the parts on a dead body. She drank a little brandy-and-water twice during the operation, and appeared quite insensible, until three or four arteries, which bled rather freely, had been tied. As there was a good deal of oozing from the whole bed of the tumour, I sponged it with cold water, on which she said, "was I going to do it ?" and appeared highly delighted when told by $\mathcal{H}_{\mathrm{r}}$. Blagg it was all over. A better proof cannot be given of the insensibility to pain, during the time she was under the influence of ether, and the return to it when it had ceased, than the fact of her complaining much, on my tying another artery, which began to bleed freely, and I did not think it necessary to place her under the influence of the vapour again. Mrs. G- (and I may remark that we have here the testimony of a lady of fortune and high character) declared, "she felt no pain during the operation." She added, "I felt nothing, for I knew nothing. The first thing I remember after I went off, was hearing something fall into a basin." This was the tumour, which $I$ threw down into a vessel near me, as soon as it had been removed. She was very cheerful an hour after the operation, remarking that the wound felt very

* I have often seen these fatty tumours acquire an enormous size. I have one now in my possession that I removed five years ago, which weighed nearly seven pounds. The tumour, in this case also, was many
pounds in weight. sore; and $I$ left her in the care of my friend, in a far better state than she could possibly have been had she suffered the usual pain of a severe and protracted operation. That we have at our command a powerful agent for removing human suffering, and disarming surgical operations of half their terrors, I am certain-I do not say in all cases, because in a patient having a tendency to apoplexy, or labouring under disease of the heart, its application might be hazardous, and no prudent practitioner will use it without first making a very careful examination of the condition of his patient. Since the above was written, $I$ have seen Mrs. Ghours after the operation,) who appears going on as well as possible.

Grove-strect, Fast Retford, Jan. 1847.

\section{OPERATIONS UPON TIIE EYE.} T'o the Euditor of TII LaXOET.

Sin,-On Saturday, Jan. 16th, three successive and successful operations were performed at the Kent Ophthalmic Institution, Maidstone, whilst the patients were under the influence of ether, administered by myself, by means of an apparatus obtained from Mr. Hooper, Pall Mall Iast.

The first case was a labourer, named $\mathrm{D}-$, ared nearly sixty, living at Bransted, a cataract patient, and the operation was the removal of a tumour, about the size of an orange, on the back of the skull, between the vertebra of the neck and the left ear. It required abont seven minutes' inhalation before the patient became insensible, when the operator, $\mathrm{Mr}$. Woolcott, made the first incision into the tumour, which was extracted in less than another minute. The patient seemed quite insensible to pain from the use of the lnife, and only evinced some symptoms of uneasiness when the sponge was applied. The vessels having been taken up, the patient exhibited symptoms, for about a minute, similar to those of noisy intoxication, which quickly subsided, and he exclaimed, "I'm coming-to now." "You nust not come-to yet," was the reply; "we are just preparing. Do you still wish to have the operation performed ?" "Yes," was the rejoinder; "you may go on; I wont flinch." He was then shown the tumour, and seemed much delighted to find that the operation had been performed whilst he was unconscious, declaring that he had not suffered the slightest pain. The wound was then strapped, and the patient arose, apparently in an excellent humour, and without exhibiting any symptom of exhaustion or fatigue.

The second case was one of fistula lacrymalis in a middleaged man, who, in a few minutes, was brought under the influence of the ether. The operation was performed without the least consciousness on the part of the petient.

The third was a case of strabismus in a boy, aged fourteen years. In this case some time was spent before the boy could be rendered sufficiently insensible for the operation. The first effect of the ether was a state of semi-intoxication, attended with a desire to go up-stairs, and it required considerable strength to provent the patient from making the attempt to do so; but in about ten minutes from the commoncement of the inhalation, he was in a profound state of intoxication. The operation having been completed, and as soon as the patient had somewhat recovered, he exclaimed, in a high tone of voice, and with great energy, "I have been going to heaven; I have been seeing the angels, and I don't know what all! I have been going' to heaven, that's all I know abont it! Angels and trmpets are blowing!" He continued to talk in this strain for ten minutes, after which he became sick and sleepy, as if recovering from a state of intoxication produced by spirituous liquors. The medical gentlemen prosent at these operations were, besides myself, and Mr. Woolcott the operator, Mr. Canton, of the Charing-cross Hospital; Dr. Huxley, of the County Lunatic Asylum; Mr. Sedgwick, Mr. Dickson, Mr. W. G. Sedgwick, Mr. Gould, and one or two other persons. Mr. Canton, who had witnessed several cases of the application of ether in the London hospitals, stated that these were the most successful cases he had seen.

Nothing could be more satisfactory than the above cases; and from the number of operations already performed in most of the public hospitals of this country and the United states of America, there can be no doubt of its applicaluility to all surgical operations, however severe and prolonged, not only on the human body, but on the bodies of animals also. Messrs. Staughton and Plomley, veterinary surgeons of this town, have, within these few days, with the assistance of myself and Mr. Woolcott, performed the most severe and difficult operations on dogs, without the least pain; and with a very simple apparatus, suggested by myself, animals can be made to respire the ether more readily than human beings. 
I have breathed the ether on several occasions, and think its effects may be divided into three stages or degrees. The first is merely a pleasurable feeling of half intoxication; the second is one of extreme pleasure, being similar to the sensations produced by breathing nitrous oxide, or laughing gas; there exists in this stage a perfect consciousness of everything said or done, but generally an incapability of motion; in this stage, also, there is not exactly an insensibility to pain, but rather an indifference, " a care-for-nothing sort of feeling;" and if surgical opcrations are done in this stage, the patients almost always recover before the operations are completed, and the results are unsatisfactory. There can be no doubt that most of the failures may be attributed to this cause, as occurred to-day in a boy operated upon by $\mathbf{M r}$. Ferguson, at King's College Hospital.

The third stage, the only one, $\dot{I}$ think, for performing operations in, is one of profound intoxication and insensibility. The individual is completely lost to pain, and to external impressions; the muscles become prostrate, the circulation lessens, and the temperature falls; but the mind is often revelling in the most pleasurable regions, as in a dream; this, no doubt, depending much upon the temperament of the individual, and probably, also, on the pliysical effects of the operation on the nerves, as very often there is a considerable moaning, and an attempt to move, when under the influence of the knife.

There appears to be some difference of opinion as to the action of ether upon the system; but there can be but little doubt, that when taken into the lungs, its elements rapidly unite with the oxygen of the arterial blood, rendering it venous, and that it stops the metamorphosis of the tissues, producing a diminution of the temperature of the body, and also a diminution of vital energy, in the same way as the vapour of alcohol, only with greater rapidity.

I remain, Sir, your obedient and humble servant, Framcis Plomeex, M.D., F.L.S., \& c.

\section{ETHERIZATION IN TETANUS.}

To the Editor of The Lancex.

Sir,-I see, by your leader of the 16th inst., that in your remarks upon the utility of etherization you state that "some have thought of its extension to medicine, and tetanus and hydrophobia have been mentioned as likely to be benefited by its use. Any such trials will assuredly end in disappointment; these diseases being diseases of motion, not of sensation," \&c. You will perhaps be pleased to learn that this opinion is strictly borne out by fact, as far as the results of a single example can be relied upon. Having recently liad a very severe case of tetanus under my care, I thought that I would give the ether a trial; I found, however, what a little reflection might have taught me, that it was even worse than useless, and that the spasms were fearfully augmented by every attempt at inhalation. As the action of ether is strictly, as far as I have been able to judge, confined to the cerebral portion of the nervous system, and as the excito-motory system is known to manifest an increase of action in proportion as volition is obliterated, (witness paraplegia, decapitation, \&c.,) it might be predicted that diseases in which the true spinal marrow is mainly implicated would not only not be reached by the ether, but would be aggravated by it. Excuse this hasty note, and believe me, dear Sir, yours obediently,

Bury St. Edmund's, Jan. 1846.

W. H. Ranking, M.D.

\section{Correspondente.}

\section{REPLY TO DR. MARSHALL HALL. To the Editor of The LaNCeT.}

Sir, - In last Saturday's Lancet appears a letter from Dr. M. Hall, in which he endeavours to vindicate himself from the charge, brought against him in the last number of the Medico-Chirurgical Review, of unjustifiable cruelty in the performance of experiments upon living animals. One would suppose, from the tone of that letter, and of the accompanying extract from his work, "On the Circulation of the Blood," that the experiment which called forth our censures had been instituted upon an animal that was deprived of sensation. That such was not the case on the occasion referred to is abundantly obvious from the very terms in which Dr. Hall's coadjutor has described the experiment in question.

"In a spaniel dog, a portion of the skull was removed by the trephine; but from the thickness of the temporal muscle, and the effusion of blood, it was very difficult to accomplish; the instrument therefore penetrated through the dura mater into the brain. The immediate effect was paralysis of the opposite side of the body; the animal, when placed on the ground, falling on that side, and being unable to rise. It nanaged, however, to struggle to the wall and comer, when, on being raised, it supported itself by leaning the paralyzed side against it. On introducing the finger, and pressing on the brain anteriorly, the eyelids closed, and the animal appeared as if asleep, breathing heavily." ...... "The cerebrum was next completely broken up and removed, and the top of the skull talyen off, The pupil of the eye became very much dilated, and the animal lost all sensation."

Can it be conceived that the infliction of such horrible suffering (for the animal, it would seem, was quite sensible at the commencement of the experiment) is necessary for the elucidation of any important truth, or for the advancement of that science on which, according to Dr. Hall, "not only the preservation, but the restoration, of strength and liealth depend." We cannot believe that even he will give the sanction of his authority to the repetition of so revolting an exhibition.

To base the justifiableness of vivisections on the permission or injunction to "liill and eat," is, to say the least of it, a strange misapplication of scriptural language. He who gave that permission, hath also told us-and how startling is the announcement - that "not even a sparrow falleth to the ground without His knowledge."

It would be easy to show how utterly opposed to the very principles which Dr. Hall has himself laid down in the extract quoted from his work on the Circulation, was the experiment upon which we have commented, not to mention some other experiments described or hinted at in the recently-published volume of the "Practical Observations and Suggestions;" but this is unnecessary at present.

The Reviewer of Dr. Hall's ObserVATIONS \&C. IN THE LAST No. OF the "Med.-Chir. Review."

$*_{*}^{*}$ The questions to be decided are-1. Are experiments on living animals, or vivisections, as they have been nicknamed, justifiable? Wesuppose there can be no doubt of the affirmative, or else the whole science of physiology falls to the ground. 2. Granting the first position, did Dr. Marshall Hall ever devise and perform an operation without such an end in view as to justify its performance? We believe not. We have ourselves seen Dr. Hall perform a great number of his experiments, and we have ever seen him follow the humane principles laid down by himself in the introduction to the Physiology of the Circulation.-ED. L.

\section{MIDWIFERY FEES.}

To the Editor of THE Lancet.

SiR,-Being an honest follower of Esculapius, I am profoundly ignorant of "Secondaries' Court," and hope to remain equally unacquainted with Mr. Secondary James, who estimates very lightly the services of a medical man.

This learned gentleman is made to state, in the Morning Chronicle of the $F$ th instant:- "Two guineas now-a-days appeared a handsome price for an accouchement. He thought few ladies who kept their carriages would give more than $5 l .5 s . "$ What will Dr. Locock say to this new and legal adjudication of fees? I should like to know, Mr. Editor, what justice there is in Mr. Secondary James fixing in so summary a manner the sum of $2 l .2 s$. No fact more than this judicial interference with our fees proves the necessity for an effective system of registration; for upon that will follow a fair system of undisputed remuneration.Yours truly,

London, Jan. 1847. Adyerso J A COBO.

\section{COURTS-MEDICAL.-WIGAN $v$. GREGORY. [LetTer from Mr. W. Robins.] To the Editor of The Lanofit.}

SIR, - I cannot help thinking the majority of your readers will be ready to admit that the cause of Wigan versus Gregory should be considered in some other light than as a mere personal dispute; and that some more lasting effect ought to be produced by it than by an ordinary nine days' wonder. In my humble opinion, there are, in this case, circumstances which must produce, sooner or later, such an impression on the pro- 